\title{
Spiritual Well-Being among Diabetic Patients
}

\author{
Sabiha Baby ${ }^{1 *}$, Owais $\mathrm{Khan}^{2}$
}

\section{ABSTRACT}

Maintaining overall health and well-being in illness can be achieved through various combinations of physical, mental, social, environmental and spiritual well-being. In recent era spirituality has emerged as a central focus of in the field of health sciences. Researchers and clinicians now believe in the important connection of spirituality, health and wellness of an individual's life. Patients living with chronic disease such as diabetes mellitus have life management challenges and difficulties that come with the disease process. The present study examined the spiritual well-being among diabetic patients. Spiritual Well-being Scale (SWBS) was administered to a sample of 50 Muslim diabetic patients (male $=23$, and female $=27$ ). Obtained data was analyzed by t-test. Results showed that there was no significant difference between male and female diabetic patients on both subscales of spiritual well being i.e., the Religious Well-being Scale $(\mathrm{t}=.451, \mathrm{p}>.05)$ and Existential Well-being Scale $(\mathrm{t}=1.11, \mathrm{p}>$ .05). This finding suggests that spiritual well- being among Muslim diabetic patients may create great encouraging results. Health documents describing the self- management procedures highlight spirituality as one of the important holistic styles that address the needs of whole person rather than isolated parts.

Keywords: Spiritual Well Being, Diabetes

There is in the body a piece of flesh, and if is good the entire body is good. However, if it is diseased, the entire body is diseased; and knows, it is the heart. -Prophet Muhammad

From the beginning of the intellectual history of mankind, scholars have been continuously trying to explore the relationship of spirituality/religiosity/faith with health conditions and outcomes of illnesses. A pioneer of modern scientific medicine, Osler (1910), wrote about "the faith that heals" (p. 1471). Meta analyses and systematic reviews support that spirituality generates a positive effect on physical and mental health conditions. Current researches in the

\footnotetext{
${ }^{1}$ Guest Teacher, Department of Psychology, AMU, Aligarh, India

${ }^{2}$ Research Scholar, Department of Psychology, AMU, Aligarh, India

*Responding Author

(C) 2016, S Baby, O Khan; licensee IJIP. This is an Open Access Research distributed under the terms of the Creative Commons Attribution License (http://creativecommons.org/licenses/by/2.0), which permits unrestricted use, distribution, and reproduction in any Medium, provided the original work is properly cited.
} 


\section{Spiritual Well-Being among Diabetic Patients}

area behavioral medicine indicate that the spirituality creates insightful effects on the body and influence health conditions of an individual in terms of positive outcomes.

Spirituality viewed as human need has been described as "that dimension of a person that is concerned with ultimate ends and values. Spirituality is that which inspires in one the desire to transcend the realm of material” (O’ Brien, 1982). Three characteristics of spirituality posited by Margaret Burkhardt (1989) include "unfolding mystery," related to one's attempt to understand the meaning and purpose of life; "harmonious interconnectedness," or an individual's relationship to other persons and/or to God; and "inner strength,” which relates to one's personal spiritual recourses and "sense of the sacred" (p. 72). Spirituality is reflections of which you are as a person, you have to have some kind of believed in yourself and in a higher being in a meaningful, purposeful way to give of yourself.

An individual's understanding of concepts such as "health" and "disease” arise from a complex interaction between personal experiences and a range of cultural factors that may include, among other things, languages, family values and norms, and religion (Helman, 2001). The relative importance of each of these factors in determining one's outlook may vary quite substantially between cultures, and, in pluralist societies such as those that now characterize many parts of the Western world, from one subculture to another. In those communities that retain a sense of the scared, the influence of religion on shaping the individual and communal view is often quite considerable (Rehman, 1998).

Health documents describing the self-management procedures highlight spirituality as one of the important holistic styles that address the needs of the whole person rather than isolated parts. Holistic health care processes promote the body's natural healing ability, and this wide-ranging approach to wellness enhances patient care efforts (American Diabetes Association, 2009). Maintaining holistic health and wellbeing in illnesses and other adversities of life has become a very serious concern of health professionals.

Spirituality is the continuing process of integrating memory, experience and anticipation within the self and it involves ongoing efforts to relate to others with altruism. Additionally, spirituality is experienced in an active sense of relatedness to the natural world's reminders of the exigencies of life and death. It functions to draw persons into a sense of connection with a power greater than and transcending themselves. This last aspect of spiritual integration is most often associated with religion, which describes the nature of the divine and prescribes ways of relating to the sacred realm. It can be defined as experiencing the presence of a power or force and experiencing closeness to that presence. Spirituality may mean being involved with organized religion, taking time to contemplate one's place in the ultimate order of things, or focusing on the things that give life meaning, such as one's family or social group. No matter what one's 


\section{Spiritual Well-Being among Diabetic Patients}

personal motivation for seeking it, spirituality can be seen as part of the journey toward becoming whole and being healthy.

Spiritual well-being is defined as having 2 dimensions: vertical and horizontal (Moberg \& Brusek, 1978). The religious (vertical) dimension involves "a sense of well-being in relation to God," and the existential horizontal dimension involves "a sense of meaning and purpose and satisfaction with life" without reference to religion (Ellison, 1983). O'Connor and colleagues (2007) demonstrated that spiritual well-being had significantly negative relationships with fatalism, hopelessness, helplessness, and anxious preoccupation. Researchers have also reported that the existential dimension has more powerful relationships than the religious dimension with higher levels of quality of life, lower-level demands related to one's illness, less uncertainty, more positive mood states, and better psychosocial adjustment (Anema, 2009; Edmondson, 2008; Landis, 1996).

Spiritual well-being can facilitate patients' healing and recovery by enhancing their inner strength, comfort, peace, wellness, wholeness, and coping abilities and by alleviating depressive symptoms, promoting mental health, increasing energy, and decreasing cancer-related distress (Walton, 1999; Yanez, et al. 2009). Spiritual well-being may be an important internal resource for persons forced to adjust to uncertainty related to long-term health problems such as diabetes mellitus (Landis, 1996).

Worldwide, prevalence of diabetes mellitus is progressively rising in a pandemic pattern. The International Diabetes Federation (IDF) predicts a $72 \%$ increase in the number of patients with diabetes from 189 million in 2000 to 224 million in 2025, and a 100\% rise of the global cost of diabetes to USD $\$ 300$ billion (IDF, 2004). Thus, the IDF has classified diabetes as an 'international disaster'.

Diabetes mellitus is a metabolic disorder that causes insulin resistance or insufficient amount of insulin to maintain normal glucose levels in the body (Becker, 2001; Franz, 2001). Researchers have demonstrated that diabetic patients present with different coping responses to the changing circumstances of this chronic illness. The patients' coping resources have a facilitating effect when facing life changing challenges (Coleman, 2003; Koenig, 2001; Lazarus \& Folkman, 1984; $\mathrm{O}$ "eBrien, 2003a). It is not surprising that diabetes may be related in some way to religious or spiritual beliefs, one coping resource in times of stress and illness is spirituality (Koenig, 2001; Koenig, 2002; O"Brien, 2003a; O"Brien, 2003c; Taylor, 2002; Wright, 2005). Although multiple factors influence how patients deal with complications of a chronic illness, spirituality has been determined to be a mediating factor in the adaptation and coping ability of patients who were faced with such challenges (Koenig, 2004a; Koenig, 2004b; Landis, 1996; Lin \& Bauer-Wu, 2003; O'Brien, 2003a; Treloar, 2002). Concerns on making life changes can increase a person's 


\section{Spiritual Well-Being among Diabetic Patients}

awareness of his or her vulnerability to chronic illnesses (Koenig, 2001; O"Brien, 2003a; O'Neill \& Kenny, 1998).

It is not surprising that diabetes-especially adult-onset (type2) diabetes-may be related in some way to religious or spiritual beliefs. Although the research in this area remains in its infancy and few studies report some interesting findings. Holistic health care seeks in part to enhance the body's natural healing ability. Recent research in the field of mind/body medicine, or psychoneuroimmunology, though, has shown that the mind can and does have a profound effect on the body. Thus, this research focuses on the role of spirituality among patients with diabetes.

\section{Research Objectives}

The present investigation examined the differences between male and female diabetic patients on spiritual well being. The following objectives have been laid down;

1. To examine the deference between male and female diabetic patients on overall Spiritual Well-Being (SWB).

2. To examine the deference between male and female diabetic patients on Religious WellBeing (RWB).

3. To examine the deference between male and female diabetic patients on Existential WellBeing (EWB).

\section{Research Questions}

1. $\quad$ Do male and female patients differ on overall Spiritual Well-Being (SWB)?

2. $\quad$ Do male and female patients differ on overall Religious Well-Being (RWB)?

3. Do male and female patients differ on overall Existential Well-Being (EWB)?

\section{METHOD}

\section{Participants}

The investigation was conducted on 50 Muslim diabetic patients, of these there were 23 male and 27 female diabetic patients. Patients were drawn from the Out Door Patients (OPD) Rajiv Gandhi Centre for Diabetes and Endocrinology, Jawaharlal Nehru Medical College, Aligarh Muslim University.

\section{Instrument}

\section{Spiritual Well-Being (SWB)}

The Spiritual Well-being Scale (SWBS) (Ellison, 1983; Paloutzian \& Ellison, 1982). The SWBS is a 20-item self-report instrument with two subscales, the Religious Wellbeing Scale (RWBS) and the Existential Well-being Scale (EBWS). The RWBS contains ten items that assess an individual's relationship with God, and there are ten items that assess a person's relationship with the physical world and other individuals (EWBS). Each item is rated on a six-point scale that ranges from (1) strongly disagree to (6) strongly agree. 


\section{RESULTS}

Table 1: Showing the difference between male and female diabetic patients on overall Spiritual Well-Being (SWB), on Religious Well-Being (RWB) and Existential Well Being (EWB)

\begin{tabular}{|l|c|c|c|c|c|}
\multicolumn{9}{c}{ Male (23) } & \multicolumn{5}{c|}{ Female (27) } \\
\hline SWB & Mean & SD & Mean & SD & t \\
\hline Total SWB & 85.13 & 8.976 & 83.00 & 7.661 & .906 \\
\hline RWB & 43.17 & 4.628 & 42.59 & 4.466 & .451 \\
\hline EXB & 41.96 & 5.465 & 40.41 & 4.405 & 1.110 \\
\hline
\end{tabular}

$\mathrm{P}<0.05^{*} \quad \mathrm{p}<0.01^{* *}$

Results of the t-test in table-1 shows that there no was significant difference found between male and female on total spiritual well being (SWB), as well as they were not significantly differ on Religious Well Being (RWB) and Existential Well Being (EWB).

\section{DISCUSSION}

The independent t-test reveals that male and female diabetic patients were not significantly differed on RWB $(\mathrm{t}=.450, \mathrm{p}>.05)$, EWB $(\mathrm{t}=1.11, \mathrm{p}>.05)$ and SWB $(\mathrm{t}=.906, \mathrm{p}>.05)$. It means both groups of patients have similar spiritual connection, and developing an authentic relationship with a Higher Power, God, or Spiritual Dimension. This result may be consistent with Landis (1996) result, he observed that spiritual well-being may be an important internal resource for persons forced to adjust to uncertainty related to long-term health problems such as diabetes mellitus. The diagnosis of chronic or life threatening illness and other adverse events can lead to spiritual struggles for patients. Patients have also noted they feel increased trust with their clinicians in the context of being asked about their spirituality (McCord, et al., 2004).

An individual's sense of spirituality can encourage hope and a feeling of adaptation, coping, or acceptance to whatever circumstance arises from a chronic illness. Spirituality may be a key locus of control when living with chronic illnesses (Koenig, 2004a; Koenig, 2004b; Landis, 1996; Lin \& Bauer-Wu, 2003; O’Brien, 2003a; Treloar, 2002).

Several other researchers have also reported that spiritual well-being can facilitate patients' healing and recovery by enhancing their inner strength, comfort, peace, wellness, wholeness, and coping abilities and by alleviating depressive symptoms, promoting mental health, increasing energy, and decreasing cancer-related distress (Walton, 1996; Yenez et al, 2009).

\section{CONCLUSION}

- Male and female diabetic patients were not differing on spiritual well-being (SWB) as well as both subscales i.e. religious well-being (RWB) and existential well-being (EWB). 


\section{Spiritual Well-Being among Diabetic Patients}

- When patients list the key characteristics of a good life, they are likely to include happiness, health, and longevity. A holistic approach to care recognizes that spirituality and health are intertwined for most patients. To be able to perform an accurate assessment and provide competent and sensitive care, the health care practitioner must consider the patient's religious and spiritual beliefs, as well as cultural mores.

\section{Acknowledgments}

The author appreciates all those who participated in the study and helped to facilitate the research process.

\section{Conflict of Interests}

The author declared no conflict of interests.

\section{REFERENCE}

American Diabetes Association (2009). http://www.diabetes.org/for-parents-andkids/livingwithdiabetes/ coping.jsp.

Anema, C., Johnson, M., Zeller, J. M., Fogg, L., \& Zetterlund, J. (2009). Spiritual well-being in individuals with fibromyalgia syndrome: relationships with symptom pattern variability, uncertainty, and psychosocial adaptation. Research \& Theory for Nursing Practice, 23 (1), 8-22.

Becker, K. (Ed.). (2001). Principles and practice of endocrinology and metabolism. Philadelphia, PA: Lippincott Williams.

Coleman, C. L. (2003). Spirituality and sexual orientation: Relationship to mental wellbeing and functional health status. Journal of Advanced Nursing, 43(5), 457-464.

Edmondson, D, Park, C. L., O Blank, T., Fenster, J. R., \& Mills M. A. (2008). Deconstructing spiritual well-being: existential well-being and HRQOL in cancer survivors. PsychoOncology, 17(2), 161-169.

Ellison, C. W. (1983). Spiritual well-being: Conceptualization and measurement. Journal of Psychology \& Theology, 11, 330-340.

Franz, M. (Ed.). (2001). Diabetes and complications: A core curriculum for diabetic educators. American Association of Diabetic Educators

Helman C. G. (2001). Culture, Health and Illness. Arnold: Landon.

International Diabetes Federation Diabetes Atlas (2e) Brussels: IDA, 2004.

Koenig, H. G. (2002). Spirituality in patient care: Why, how, when, and what. Philadelphia, PA: Templeton Foundation Press.

Koenig, H.G. (2001). Handbook of religion and health. New York: Oxford University Press

Koenig, H.G. (2004a). Religion, spirituality, and acute care hospitalization and long term care by older patients. Archives Internal Medicine, 164, 1579-1585.

Koenig, H.G. (2004b). Religion, spirituality, and medicine: Research findings and implications for clinical practice. Southern Medical Journal, 97(12), 1194-1200.

Landis, B.J. (1996). Uncertainty, spiritual well-being, and psychosocial adjustment to chronic illness. Issues Ment Health Nurs, 17, 217-231.

Lazarus, R., \& Folkman, S. (1984). Stress, appraisal, and coping. New York: Springer.

Lin, H., \& Bauer-Wu, S. (2003). Psycho-spiritual well-being in patients with advanced cancer: an integrative review of the literature. Journal of Advanced Nursing, 44(1), 69-80. 


\section{Spiritual Well-Being among Diabetic Patients}

McCord, G., Gilchrist, V.J, Grossman, S.D., King, B.D., McCormick, K.F. \& Oprandi, A.M. (2004). Discussing spirituality with patients: A rational and ethical approach. The Annals of Family Medicine, 2(4), 356-361.

Moberg, D. O., \& Brusek, P. M. (1978). Spiritual well-being: A neglected subject in quality of life research. Social Indicators Research, 5, 303-323.

O’Connor, M. et al (2007). Relationships between quality of life, spiritual well-being, and psychological adjustment styles for people living with Leukaemia: An exploratory study. Mental Health Religion and Culture, 10(6), 631-647.

O"Brien, M.E (2003c). Spirituality in nursing: Standing on holy ground, (2nd Ed.). Sudbury, MA: Jones and Barlett.

O'Brien, M.E. (2003a). An experiment in parish nursing practice: A middle-range theory of spiritual well-being in illness. In Parish Nursing Healthcare Ministry within the Church, (pp.99-114). Boston, MA: Jones and Bartlett Publishers.

O"e Neill, D. P., \& Kenny, E. (1998). Spirituality and chronic illness. Image- the Journal of Nursing Scholarship, 30(3), 275-280.

Osler, W.: 1910, 'The faith that heals. The British Medical Journal, 1, 1470-1472.

Paloutzian, R. F., \& Ellison, C.W. (1982). Loneliness, spiritual well-being, and quality of life. In L. A. Peplau \& D. Perlman (Eds.), Loneliness: A sourcebook of current theory, research and therapy. New York: Wiley.

Rehman, F. (1998). Health and Medicine in the Islamic Tradition. ABC: Chicago. Health disease and the human heart

Taylor, E.J. (2002). Spiritual care: Nursing theory, research, and practice. Upper Saddle River, NJ: Prentice Hall.

Treloar, L. (2002). Disability, spiritual beliefs and the church: the experiences of adults with disabilities and family members. Journal of Advanced Nursing, 40(5), 594- 603.

Walton J. (1999). Spirituality of patients recovering from an acute myocardial infarction. Journal Holist Nursing, 17(1), 34-53.

Wright, L. (2005). Spirituality, suffering, and illness: Ideas for healing. Philadelphia, PA: F.A. Davis Company.

Yanez, B., Edmondson, D., Stanton, A.L., Park, C.L., Kwan, L. \& Ganz, P.A. (2009). Facets of spirituality as predictors of adjustment to cancer: relative contributions of having faith and finding meaning. Journal of Consultant Clinical Psychology, 77(4), 730-741.

How to cite this article: S Baby, O Khan (2016), Spiritual Well-Being among Diabetic Patients, International Journal of Indian Psychology, Volume 3, Issue 4, No. 65, ISSN 2348-5396 (e), ISSN: 2349-3429 (p), DIP: 18.01.141/20160304, ISBN: 978-1-365-34680-4 